\title{
THE ROLE OF FORECASTING PARAMETERS IN REDUCING BULLWHIP EFFECT
}

\author{
Parisa Alizadeh* \\ *Inventory Control Department, Mahghol Co., Karaj, No. 9, Deihim Alley, Pak-e-shomali st., \\ Sattarkhan Ave., Tehran, Iran \\ E-mail: palizadeh@alum.sharif.edu
}

\begin{abstract}
:
This paper investigates how selecting appropriate forecasting parameters could be useful in reducing ordering variances (i.e. bullwhip effect) moving up stream a four-level supply chain. We examined 40 different scenarios for each echelon of supply chain in order to find governing rules in determination the best forecasting parameters. Relying on extensive spreadsheet computation we found some interesting results which need more investigations to be accepted as a general rule for all forecasting techniques. The results shown in tables and charts demonstrate that increasing number of periods used for initial average calculating in smoothing formula ( $\mathrm{T})$ decreases ordering variances. Moreover, increasing weighting factor $(\alpha)$ in exponential smoothing formula results in increasing variances of orders; that is, it results in intensified bullwhip effect. Regarding these two findings, we will show that simultaneous increase of forecasting parameters $(T, \alpha)$ will alleviate ordering variances or bullwhip effect. The most important limitation of the research is that there are some informal local producers whose levels of production could not be exactly determined. We had to simply add their production variances to the demand variance of each echelon. However, designing computerized systems for archiving data during the time will be useful for finding the variances pattern. This investigation was carried out on the real supply chain of a dairy company (Mahghol Co.) and the results made good progress in improving supply chain management and inventory policy.
\end{abstract}

Key Words: Supply Chain Management, Bullwhip Effect, Exponential Smoothing, Demand Forecasting

\section{INTRODUCTION}

The Bullwhip Effect (also called demand amplification effect, whiplash effect or Forrester effect) is an undesirable phenomenon in forecast-driven supply chains. This effect that was first introduced by J. Forrester's Industrial Dynamics (1961) is the amplification of the demand (order) variance moving up the supply chain, from customer to factory (Portes \& Vieira, 2006). The effect means that variability in orders and stocks increases when we move upstream the supply chain; that is, when we move from final customer to the factory (Lee et al., 1997a). This increasing variance is the cause of different levels of ineffectiveness in upstream echelons of the chain and its reduction will be result in more efficiency and profitability (Metters, 1997). Other authors such as Blanchard (1983), Blinder (1982), and Kahn (1987) also showed that there was bullwhip-like inventory volatility in supply chains.

The beer game (Sterman, 1989) which is used in supply chain management courses illustrates the bullwhip effect phenomenon. As the Cachon et al. (2007) discusses, this effect could be also considered at a macro-level; that is, at the level of an industry as a whole. However, their findings showed that the intensity of this unfavorable phenomenon varies among different types of industries; such as, manufacturing industries, retail industries, seasonal industries, etc.

Bullwhip effect has some consequences: 
Firstly, it results in the need for providing more inventories and therefore higher capacities which in turn gives rise to expenses. Second, bullwhip effect will create backlogs which in turn will result in some undesirable outcomes; such as, need for more personnel and working, penalties, increasing speed of transportation, etc. Moreover, these backlogs may result in some other consequences like poor quality, the bad image of the supplier which could not be measured easily (Dolgui \& Proth, 2010). More specifically, bullwhip effect is accompanied by two other effects in supply chain: oscillation and phase lag effects. Oscillation effect means that all of the chain's echelons experience some business cycles of prosperity and recession which tend to be more leveled during the time. In addition there is a phase lag equal to the lead time between the cycles of the members. In other words, the pattern of ordering variances of any member conveys to the previous member in the chain with a time lag equal to the lead time (Sterman, 2006).

Based on Lee et al. (1997b) there are four major causes of the bullwhip effect:

Demand forecast updating: When the exact form of final customer demand process is unknown for retailer, various forecasting methods using historical data are applied in order to estimate the amount of demand. Consequently, the retailer's order to wholesaler and the wholesaler's order to the factory will vary. In other words, each echelon of supply chain has to forecast the demand of its downstream customer. In such situation, any variance in forecasting demand will be transmitted to the previous step; therefore, will be amplified up streaming the chain.

Order batching: Ordering in batches is the main inventory policy in many cases. The policy results in the necessity of storing higher stock to avoid depletion.

Price fluctuation: Price increase or decrease results in unexpected behaviors of customers; for example, when the prices decrease customer rationally buys more, and vice versa. These unforeseen behaviors give birth to bullwhip effect.

Rationing and shortage gaming: This cause is similar to price fluctuation since when customers start to buy more than their needs in order to satisfy their future needs. The result of such behavior is demand exceeding supply.

In general, four remedial actions are proposed for decreasing bullwhip effect:

Avoid Multiple Demand Forecast Updates: In order to avoid multiple demand forecast update by each member of chain, demand data of a downstream member could be shared with upstream member. Partners in a supply chain can share data by means of EDI (electronic data interchange). They can also make advantage of vendor-managed inventory policy (VMI) (Disney \& Towill, 2003) or continuous replenishment program (CRP). Production techniques such as just-in-time (JIT) could be useful too.

Break Order Batches: Ordering smaller batches or more frequent resupply will be useful for decreasing bullwhip effect. Moreover, receiving consumption data on a fixed and periodic program from downstream customers helps an upstream partner not to be surprised by unusual orders. Partners of the chain can exploit computer-assisted ordering (CAO), electronic data interchange (EDI), and trading process network to handle the information and consequently the costs of ordering.

Stabilize Prices: Reducing frequency and the level of wholesale price discounting is another way to control bullwhip effect.

Eliminate Gaming in Shortage: By sharing information about the capacity and inventory, manufacturers will be able to relieve customers' anxiety to buy more than their present needs. Moreover, the possibility of placing orders in advance of sales season and considering penalties for returning or canceling orders by downstream partner will be helpful for reducing bullwhip effect.

There is a variety of studies on different approaches for reducing bullwhip effect. Bourland et al. (1996) showed that eliminating delays in receiving customer information by supplier will be regarded as one of the most important factors to reduce bullwhip effect. Thonemann (2002) introduces a mathematical model to improve the performance of supply chain (SC) by sharing demand information in a three-level chain. Similarly, Croson \& Donohue (2003) showed that sharing POS (point of sale) data among the members of a supply chain can be helpful in reducing bullwhip effect. They demonstrated this improvement 
by comparing order decisions and real demand. Chandra \& Grabis (2005) used simulation modeling to investigate the effect of a material requirements planning (MRP) based inventory control approach on bullwhip effect. The results showed that the proposed model reduced bullwhip effect and resulted in better inventory performance. Boute et al. (2006) introduces an integrated production and inventory model in order to reduce demand variation up streaming a two-level supply chain. They represented that considering order effect on delay time resulted in a steadier ordering pattern without need to increasing inventory level. Gealman \& Disney (2007) proved that a suitable policy using an inventory feedback controller could be resulted in reducing bullwhip effect. Moreover, they showed that bullwhip effect could be even neglected providing choosing appropriate feedback parameters. Hoborg et al. (2007) investigated different inventory policy; such as, in hand inventory and total inventory in a two-level chain. They showed that in hand inventory policy is an unstable policy; however, total inventory policy is not. As the Liu \& Wang (2007) analyzed, the type of forecasting method; such as such as moving average (MA) method, exponentially weighted moving average (EWMA) method or mean square error-optimal (MSE-optimal) affects decreasing the bullwhip effects. Ouyang (2007) studied the effect of data sharing in SC on its stability and reducing bullwhip effect. The results showed that sharing information among the chain's member lessened bullwhip effect; however, did not eliminate it completely. Wu \& Katok (2006) investigated the effect of education and communication on bullwhip effect. They showed that education resulted in improving each echelon's understanding and knowledge; however, as long as it was not shared among the members of the chain in did not reduce bullwhip effect. Janamanchi \& Burns (2007) studies the effect of lengthening inventory replenishment on bullwhip effect reduction. They showed that this strategy could be considered as a complementary policy to other measures for reducing bullwhip effect; such as, information sharing. Buchmeister et al. (2008) investigated two different stock keeping policies for all echelons in a supply chain. They considered stable demand with a single 5\% change and changing demand in periodic $10 \%$ increases and the same decrease later. After studying two stock one and two periods' demand, they understood that coordinating the activities of the members of the chain will decrease the variability of orders and stocks. Boute \& Lambrecht (2009) used spreadsheet simulation to show that adjusting the parameters of the inventory control policy reduces the bullwhip effect. Similar to their study, in the following section we are going to investigate the role of adjusting the parameters of demand forecasting policy to reduce the bullwhip effect.

\section{METHODOLOGY}

As it was mentioned before, demand forecasting is one of the causes for bullwhip effect in supply chains. There are various forecasting methods; however, the most applicable ones are moving average (MA) and exponential smoothing (ES).

Exponential smoothing uses the equation (1) to calculate forecasted value:

$$
\mathrm{F}_{\mathrm{t}+1}=\alpha \mathrm{D}_{\mathrm{t}}+(1-\alpha) \mathrm{F}_{\mathrm{t}}
$$

Where:

- $D_{t}$ is the actual value of demand for period $t$

- $F_{t}$ is the forecasted value of demand for period $t$

- $\alpha$ is the weighting factor, which ranges from 0 to 1

- $\mathrm{t}$ is the current time period.

The smoothed value becomes the forecast for period $t+1$. Generally, we know that a small $\alpha$ provides a detectable and visible smoothing. While a large $\alpha$ provides a fast response to the recent changes in the time series but provides a smaller amount of smoothing.

Exponential smoothing method has some significant advantages that make it very suitable for demand forecasting in many supply chains:

- Simplicity 
- Possibility to adjust the influence of recent data.

However, there are some shortcomings related to this method too. For example, the method is not applicable when trend exists. Moreover, there is no definite rule for choosing its main parameter $(\alpha)$; that is, it is chosen in a try and error manner.

The characteristics of the supply chain which we are going to study are as follows:

- The studied supply chain is a real one in dairy industry which is composed of four levels: retailer, wholesaler, distributor, and factory (see Figure 1)

- There are informal local producers in dairy industry which randomly provide some part of total demand throughout the network of final customers. The factory cannot forecast their activities. Therefore, final demand varies between 30-50 units per week (see Table I). However, since the demand trend is relatively stable and it varies around an average, using exponential smoothing method for forecasting demand is allowed.

- Inventory control policy is based on backorder policy.

- Ordering is done at the every weekend.

- Lead time for each echelon is 1 week.

- Maximum data for forecasting purpose is available for 40 weeks.

- Each echelon use exponential smoothing technique in order to forecast orders.

Increased demand forecasting variance

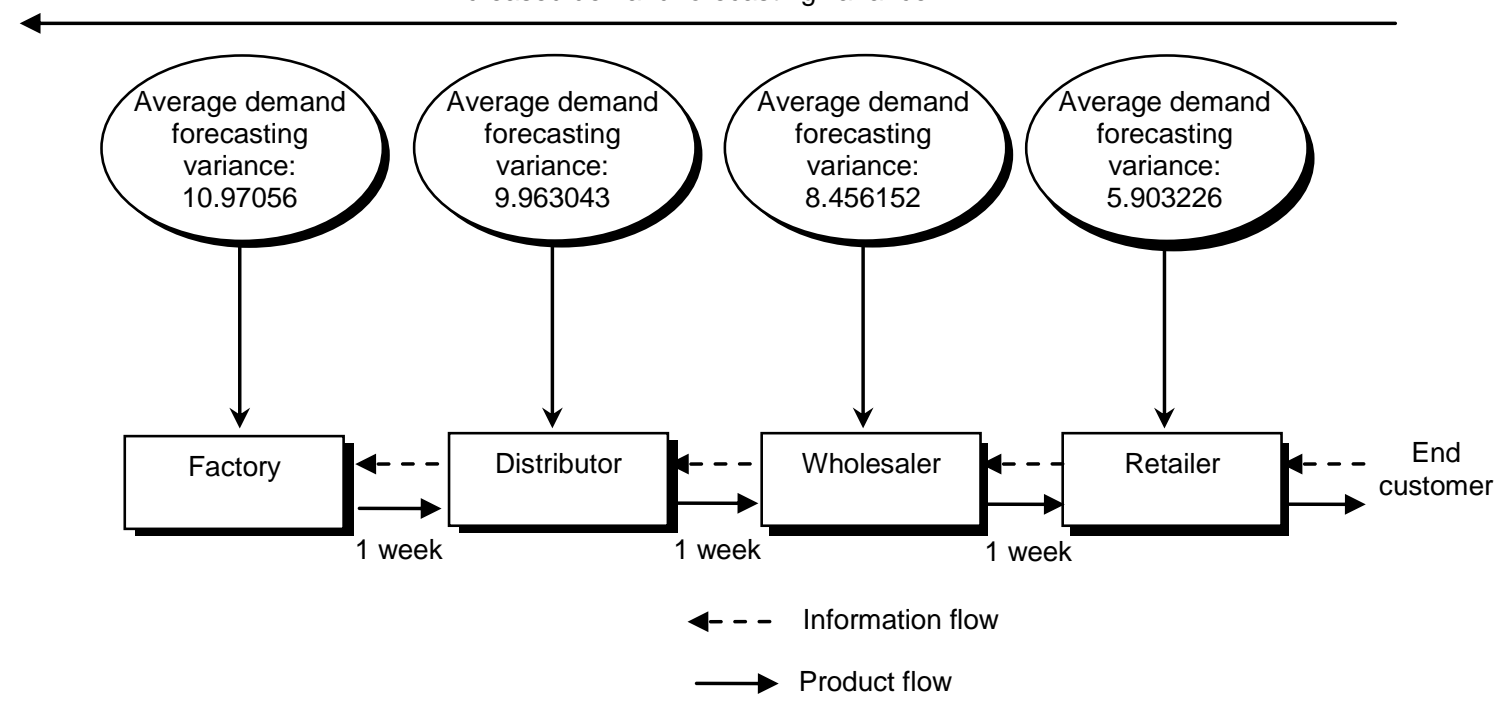

Figure 1: Schematic Representation of the Studied Supply Chain Source: Adapted from (Ports \& Vieira, 2006).

Table I: Final Customer's Demand.

\begin{tabular}{|c|c|c|c|c|c|c|c|}
\hline Week & $\begin{array}{c}\text { Demand } \\
\text { (units) }\end{array}$ & Week & $\begin{array}{c}\text { Demand } \\
\text { (units) }\end{array}$ & Week & $\begin{array}{c}\text { Demand } \\
\text { (units) }\end{array}$ & Week & $\begin{array}{c}\text { Demand } \\
\text { (units) }\end{array}$ \\
\hline 1 & 35 & 11 & 36 & 21 & 39 & 31 & 40 \\
\hline 2 & 42 & 12 & 42 & 22 & 40 & 32 & 35 \\
\hline 3 & 36 & 13 & 39 & 23 & 37 & 33 & 39 \\
\hline 4 & 41 & 14 & 43 & 24 & 45 & 34 & 37 \\
\hline 5 & 40 & 15 & 38 & 25 & 46 & 35 & 43 \\
\hline 6 & 43 & 16 & 34 & 26 & 38 & 36 & 44 \\
\hline 7 & 40 & 17 & 41 & 27 & 48 & 37 & 38 \\
\hline 8 & 39 & 18 & 44 & 28 & 33 & 38 & 45 \\
\hline 9 & 38 & 19 & 35 & 29 & 40 & 39 & 47 \\
\hline 10 & 35 & 20 & 36 & 30 & 42 & 40 & 40 \\
\hline
\end{tabular}


In our study, we are going to investigate reducing bullwhip effect through adjusting forecasting parameters in a four-level supply chain. More exactly, the aim of the research is to show the importance of choosing appropriate forecasting parameters for reducing bullwhip effect. The main forecasting parameteres in exponential smoothing technique are weighting factor $(\alpha)$ and average amount used as initial value in smoothing formula which is dependent on the number of periods used for average calculating. By changing each parameter we will have a new forecasting scenario. Since we have two parameters considering multiplication principle, number of ways for changing the first parameter times the number of ways for changing the second one equls the total forecasting scenarios. Figure 2 shows the different combination of forecasting parameteres which result in different ordering patterns.

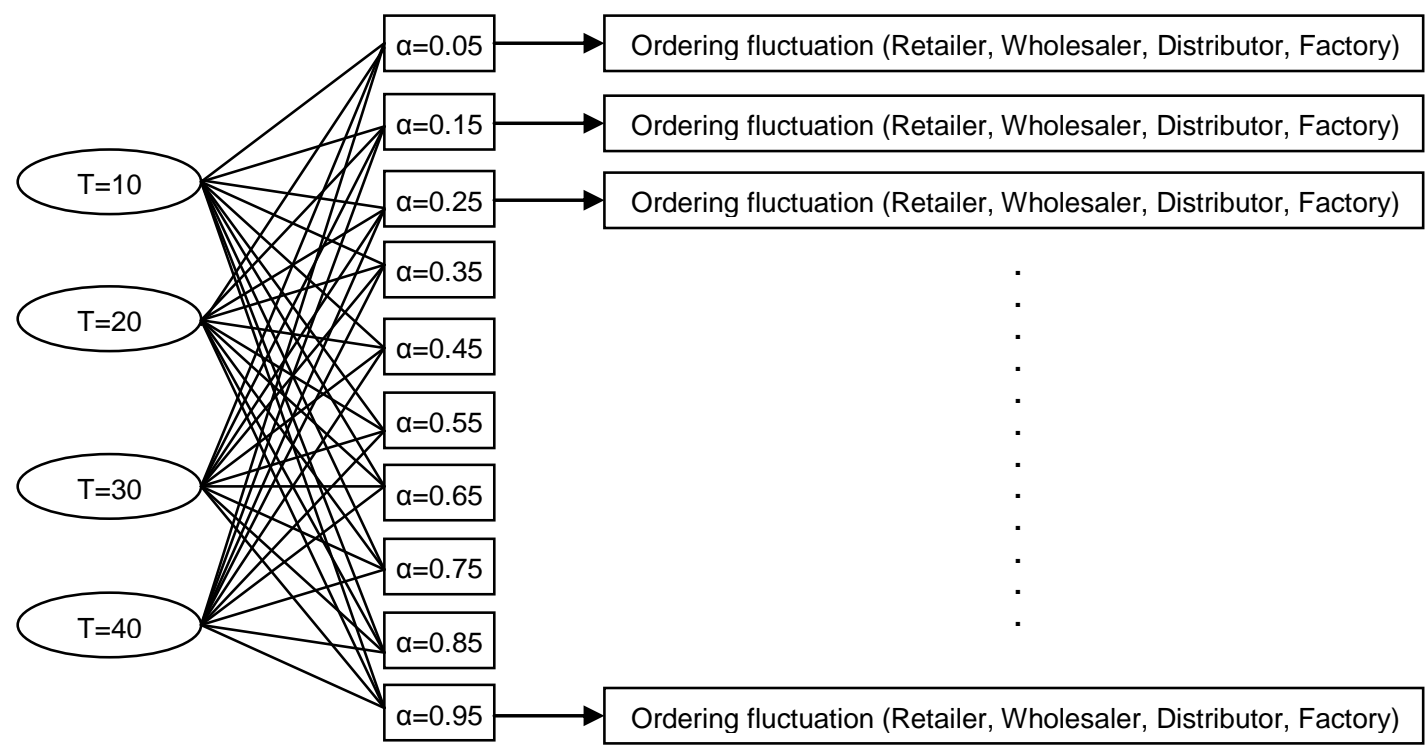

Figure 2. Different Scenarios of Forecasting Parameteres.

For each combination we calculated the variance of mambers' ordering. For example when the data is available for 20 periods $(\mathrm{T}=20)$ and the weighting factor is $0.45(\alpha=0.45)$ ordering variances is calculated as equations (2-5):

$$
\text { i) } \operatorname{Var}_{\text {Retailer }}=\frac{\sum_{i=0}^{19}\left(F_{R_{i}}-\bar{F}_{R}\right)^{2}}{19}
$$

Where:

$$
\bar{F}_{R}=\frac{\sum_{i=0}^{19} F_{R_{i}}}{20}
$$

$F_{R_{i}}$ : Forecasted demand of final customer by Retailer

$F_{R_{0}}=D_{1} ; \quad D_{1}$ : Real demand of final customer for week 1

$F_{R_{i}}=\alpha D_{j}+(1-\alpha) F_{R_{i-1}}$

$D_{j}$ : Real demand of final customer for weeks (2-20)

$i=1, \ldots, 19$

$j=i+1$

ii) $\operatorname{Var}_{\text {Wholesaler }}=\frac{\sum_{k=-1}^{18}\left(F_{W_{k}}-\bar{F}_{W}\right)^{2}}{19}$ 
Where:

$$
\bar{F}_{W}=\frac{\sum_{k=-1}^{18} F_{W_{k}}}{20}
$$

$F_{W_{k}}$ : Forecasted demand of retailer by wholesaler

$$
F_{W_{(-1)}}=F_{R_{0}}=D_{1}
$$$$
F_{W_{k}}=\alpha F_{R_{i}}+(1-\alpha) F_{W_{k-1}}
$$$$
k=0, \ldots, 18
$$

$i=k+1$

iii) $\operatorname{Var}_{\text {Distributor }}=\frac{\sum_{l=-2}^{17}\left(F_{D_{l}}-\bar{F}_{D}\right)^{2}}{19}$

Where:

$$
\bar{F}_{D}=\frac{\sum_{k=-2}^{17} F_{D_{l}}}{20}
$$

$F_{D_{l}}$ : Forecasted demand of wholesaler by distributor

$$
F_{D_{(-2)}}=F_{W_{(-1)}}=F_{R_{0}}=D_{1}
$$$$
F_{D_{l}}=\alpha F_{W_{k}}+(1-\alpha) F_{D_{l-1}}
$$$$
l=-1, \ldots, 17
$$$$
k=l+1
$$

iv) $\operatorname{Var}_{\text {Factory }}=\frac{\sum_{m=-3}^{16}\left(F_{F_{m}}-\bar{F}_{F}\right)^{2}}{19}$

Where:

$$
\bar{F}_{F}=\frac{\sum_{m=-3}^{16} F_{F_{m}}}{20}
$$

$F_{F_{m}}$ : Forecasted demand of distributor by factory

$F_{F_{(-3)}}=F_{D_{(-2)}}=F_{W_{(-1)}}=F_{R_{0}}=D_{1}$

$F_{F_{m}}=\alpha F_{D_{l}}+(1-\alpha) F_{F_{m-1}}$

$m=-2, \ldots, 16$

$l=m+1$

\section{FINDINGS}

\subsection{Relationship between ordering variances and forecasting parameters}

Table II shows the results of the variance calculations which were explained in the previous section for all 40 combinations of forecasting parameteres.

The results has been also demonstrated in Figure 3 (a) to (d) by number of periods used for average calculating in smoothing formula. Looking carefully at these figures, we get some interesting conlusions:

1) Generally speaking, Figure 3 (a) to (d) show that increasing weighting factor $(\alpha)$ in exponential smoothing formula results in increasing variances of orders for all of the 
supply chain's members. In other words, when we rely more on the real demand and neglect forecasted amount of the previous period, the ordering variance will grow.

2) Increasing number of periods used for average calculating in smoothing formula (from $\mathrm{T}=20$ or 30 to $\mathrm{T}=40$ ) decreases ordering variances about 3-4 units for each echelon. Moreover, as in could be seen in Figure 3 (d) the variances are more convergent that means less bullwhip effect in the supply chain. The reason is that by increasing the number of periods used for average calculating we get more accurate and smoothed initial amount based on the past data in order to calculate exponential smoothing formula.

3) For $\mathrm{T}=30$ or 40 , it is observed that by increasing weighting factor from 0.05 to 0.95 ordering variances increase less intensly comparing $\mathrm{T}=10$ or 20 . In other words, relying on a larger number of past data for averaging demands will help us to compensate less dependence on real demand amounts. It means that for weightening factors less than 0.55 that our dependece on real demand amount decreases, the ordering variances of all members will have less differences (see Figure 3 (c), (d)). In other word, in situations where the recent data is of great importance for supply chain managers it is recommended to rely on a wider horizon to calculate average amount in forecasting formula in order to prevent intense increase of bullwhip effect.

Table II: Ordering Variances of Each SC' Echelon for Different Forecasting Parameteres.

\begin{tabular}{|c|c|c|c|c|c|c|c|c|c|c|c|}
\hline $\begin{array}{l}\text { Number } \\
\text { of periods } \\
\text { used for } \\
\text { averaging }\end{array}$ & $\begin{array}{l}\text { Weighting } \\
\text { factor } \\
\text { SC's } \\
\text { echelons }\end{array}$ & $\alpha=0.05$ & $\alpha=0.15$ & $\alpha=0.25$ & $\alpha=0.35$ & $\alpha=0.45$ & $\alpha=0.55$ & $\alpha=0.65$ & $\alpha=0.75$ & $\alpha=0.85$ & $\alpha=0.95$ \\
\hline \multirow[t]{2}{*}{$\mathrm{T}=10$} & Distributor & 0.336253 & 2.500134 & 3.468398 & 8.313939 & 10.65346 & 12.39132 & 13.55527 & 14.23074 & 15.53791 & 14.61914 \\
\hline & Factory & 0.535507 & 3.604324 & 7.252278 & 10.25277 & 12.32626 & 13.58219 & 14.24091 & 14.52342 & 14.60954 & 14.62221 \\
\hline $\mathrm{T}=20$ & Retailer & 0.133249 & 0.672814 & 1.552001 & 2.701562 & 4.024473 & 5.512119 & 7.226365 & 9.267423 & 11.76088 & 14.86005 \\
\hline \multirow{4}{*}{$T=30$} & Retailer & 0.99555 & 1.879738 & 2.42954 & 3.286848 & 4.397803 & 5.72467 & 7.292892 & 9.165247 & 11.4257 & 14.17678 \\
\hline & Wholesaler & 1.066578 & 2.381941 & 3.817144 & 5.756761 & 7.928371 & 10.10472 & 12.11415 & 13.8053 & 15.03741 & 15.69095 \\
\hline & Distributor & 1.199178 & 3.247831 & 5.710406 & 8.45994 & 10.97854 & 12.99085 & 14.40875 & 15.26254 & 15.66221 & 15.77051 \\
\hline & Factory & 1.383921 & 4.301027 & 7.609907 & 10.6808 & 12.99141 & 14.47492 & 3624 & 15.64543 & 15.75779 & 15.7745 \\
\hline \multirow{2}{*}{$\mathrm{T}=40$} & Retailer & 1.560456 & 2.08766 & 2.463533 & 3.208488 & 4.187479 & 5.346822 & 6.700529 & 8.299166 & 10.21506 & 12.5402 \\
\hline & Wholesaler & 1.583941 & 2.450277 & 3.608416 & 5.294447 & 7.183421 & 9.06279 & 10.78446 & 12.22395 & 13.26807 & 13.82081 \\
\hline
\end{tabular}

\subsection{Amplification (bullwhip), oscillation, and phase lag effects}

- Amplification (bullwhip) effect

In order to investigate amplification or bullwhip effect we consider 40 period forecasting data (i.e. $T=40$ ) as a case in point. As it has shown in Figure 4 (a), (b) there is an order amplification up streaming the supply chain; that is, when we move from the retailer to the factory. In other words, factory's ordering variances is more than distributor's, wholesaler's, and retailer's. The bullwhip effect is also observed for $T=10, T=20$, and $T=30$.

Moreover, comparing Figure 4 (a) and (b) it is clear that increasing weighting factor (from $\alpha=0.15$ to $\alpha=0.85$ ) results in intensified bullwhip effect. This result confirms our previous finding because as we observed in the previous section more relying on the real data and neglecting forecasted amount for the previous period increases bullwhip effect.

- Oscillation effect

Besides the bullwhip effect, we observe an oscillation effect too. That is, there are some business cycles for all of the chain's echelons that tend to be more leveled in the final periods. As it could be seen from the figures, these cycles follow similar pattern for all of the members of the chain.

- Phase lag effect

In addition to the above effects, a phase lag effect is also clear in the following figures; that is, ordering fluctuations for each of the chain's echelons which are increased in size transfers to the next member of the chain with a phase lag equals to the lead time of ordering (in our case study lead time is 1 week). 


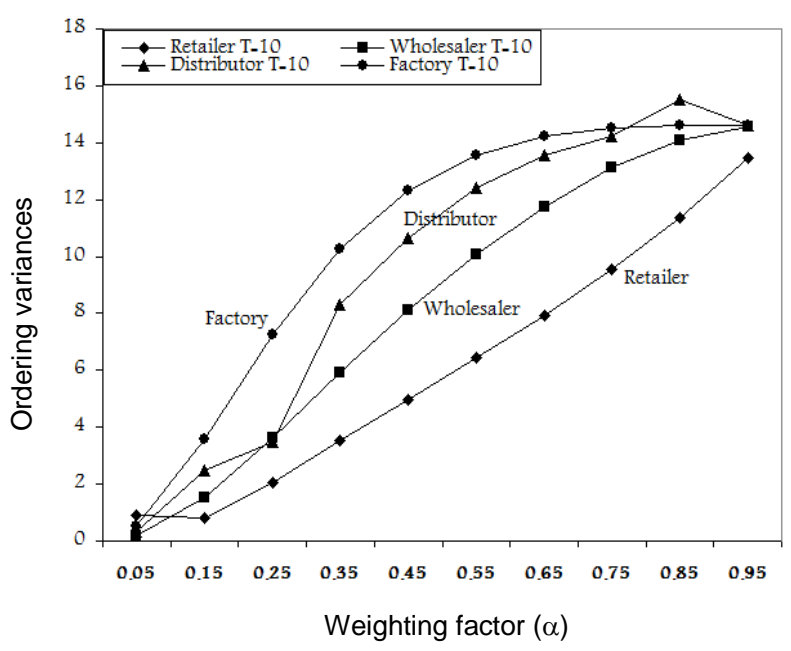

(a) Ordering variances for $\mathrm{T}=10$ and different weighting factors

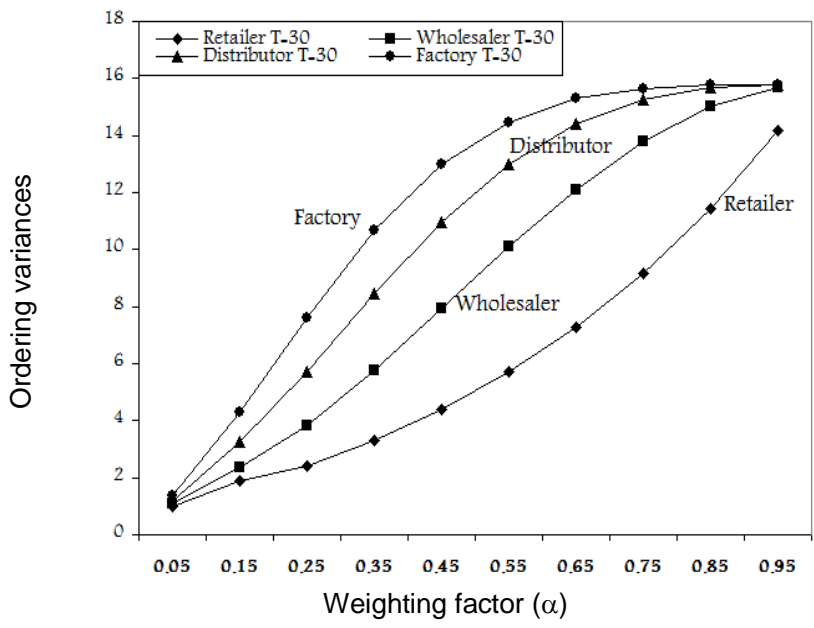

(c) Ordering variances for $\mathrm{T}=30$ and different weighting factors

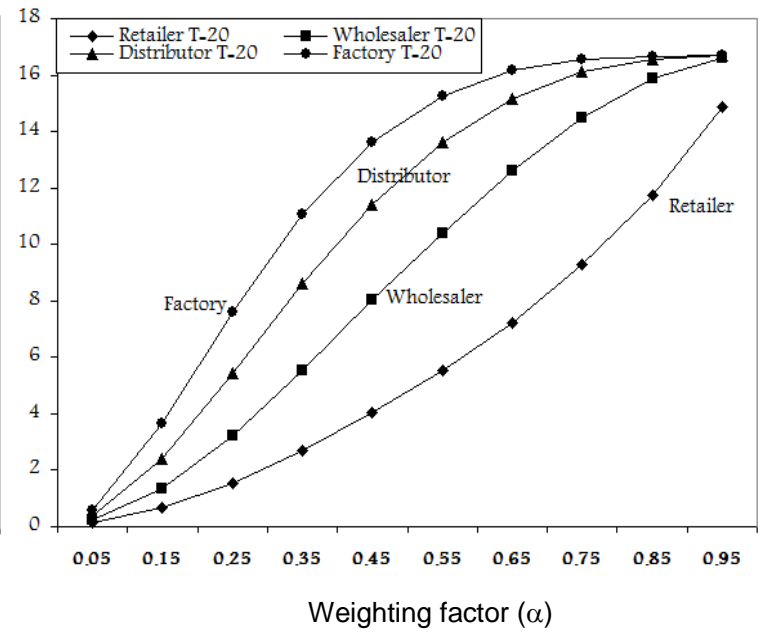

(b) Ordering variances for $\mathrm{T}=20$ and different weighting factors

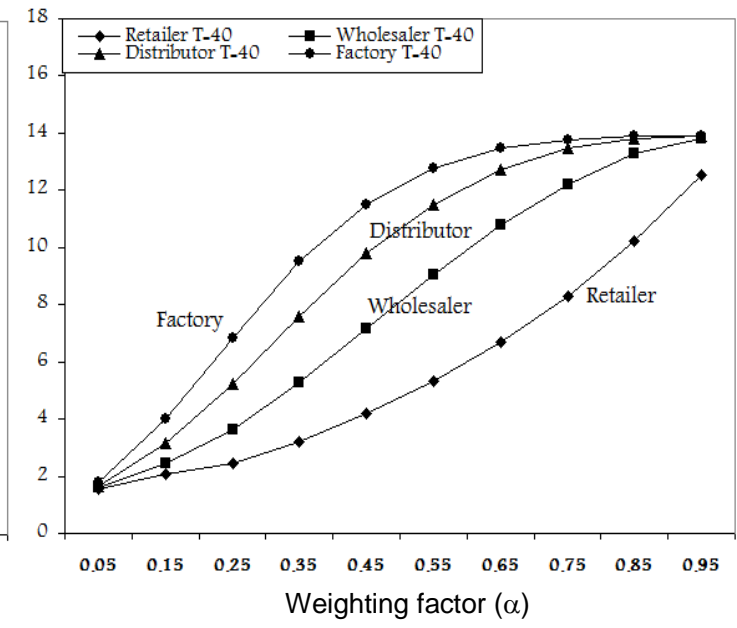

(d) Ordering variances for $\mathrm{T}=40$ and different weighting factors

Figure 3: The Influence of the Number of Periods Used for Forecasting On Ordering Variances (Bullwhip Effect).

\section{CONCLUSION}

A wide variety of studies have been conducted on the undesirable phenomenon in forecastdriven supply chains called "bullwhip effect". Based on previous literature we found a missing piece about the phenomenon; that is, the influence of choosing appropriate forecasting parameters in order to reduce the bullwhip effect. Therefore, we considered a four-level supply chain in dairy industry whose members use exponential smoothing formula to forecast their customer's demand. The formula has two main parameters: weighting factor $(\alpha)$ and initial average amount of $\mathrm{T}$ consecutive periods used for trigging exponential smoothing formula. We supposed 10 different cases for $\alpha$ and 4 ones for T; consequently, we had 40 scenarios for analysis the influence of the parameters. Results which are shown in the form of diagrams reveal the following findings: 


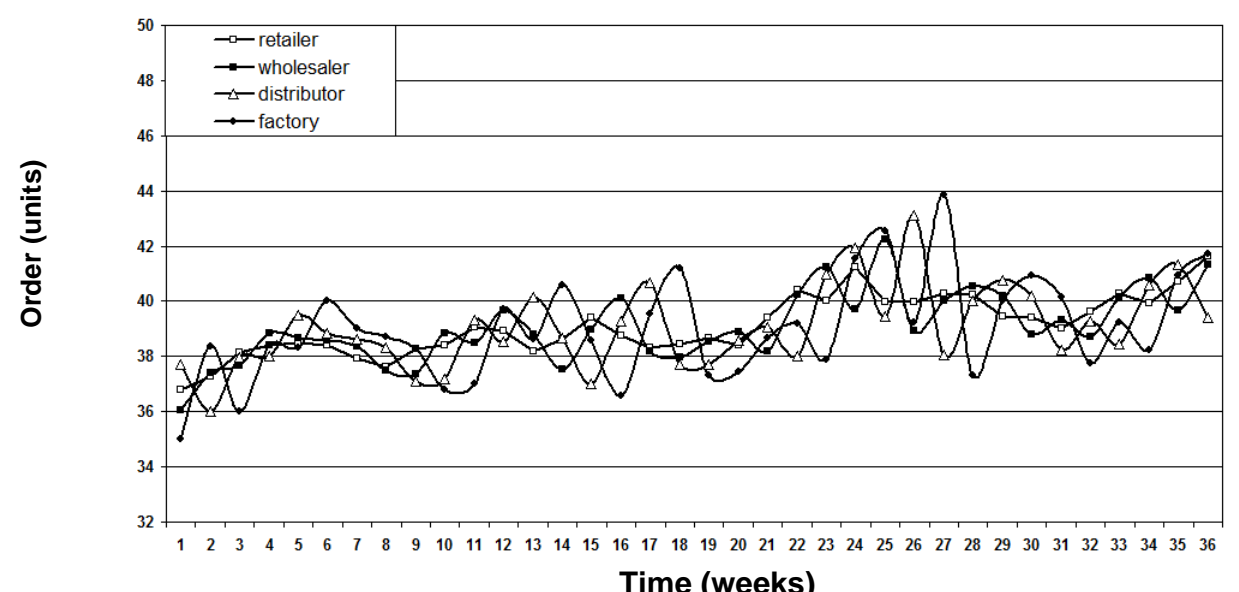

(a) $\alpha=0.15, T=40$

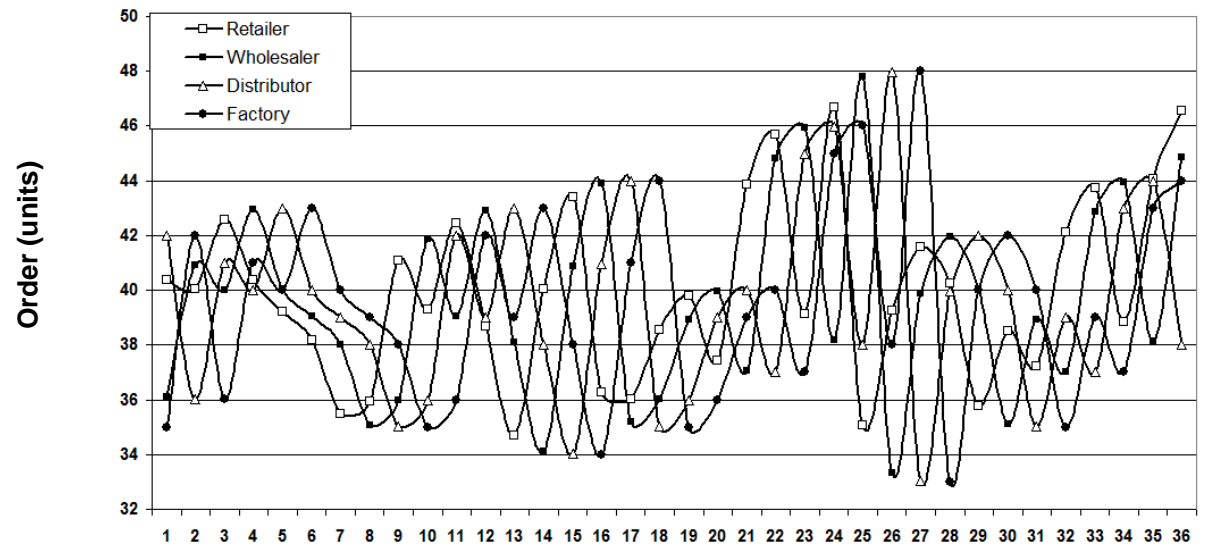

Time (weeks)

(b) $a=0.85, T=40$

Figure 4: Weekly Orders Fluctuations of Each Echelon in Supply Chain.

- Increasing the number of periods used for average calculating in smoothing formula (from $\mathrm{T}=20$ or 30 to $\mathrm{T}=40$ ) decreases ordering variances about 3-4 units for each member of supply chain.

- Increasing weighting factor $(\alpha)$ in smoothing formula results in increasing ordering variances for all of the chain's members; that is, it results in intensified bullwhip effect.

- Regarding the two above conclusion, we discovered that if we simultaneously increase the number of periods used for average calculating in smoothing formula $(T)$ and weighting factor $(\alpha)$, ordering variances increase less intensly. In other words, regrading the importance of the recent data, it is recommended to use a larger horizon for averaging data in order to reduce bullwhip effect.

- Archiving past data is of vital importance in supply chain management. Therefore, designing comupterized systems for saving data during the time is recommended for increasing the effectiveness of supply chain management.

The above findings are valid for supply chains in which members use exponential smoothing technique to forecast demand. However, there may be need for analyzing other forecasting methods to find specific rules governing them.

\section{REFERENCES}

[1] Blanchard, O. J. (1983). The Production and Inventory Behavior of the American Automobile Industry, Journal of Political Economy, Vol. 91, 365-400

[2] Blinder, A.S. (1982). Inventories and sticky prices, American Economic Review, Vol. 72, 334 349 
[3] Bourland, K.E.; Powell, S.G.; Pyke, D.F. (1996). Exploiting timely demand information to reduce inventories, European Journal of Operational Research, Vol. 92, 239-253

[4] Boute, R. N.; Disney, S. M.; Lambrecht, M. R.; Houdt, B. V. (2007). An integrated production and inventory model to dampen upstream demand variability in the supply chain, European Journal of Operational Research, Vol. 178, 121-142

[5] Boute, R. N.; Lambrecht. M. R. (2009). Exploring the bullwhip effect by means of spreadsheet simulation, INFORMS Transactions on Education, Vol. 10, 1-9

[6] Buchmeister, B.; Pavlinjek, J.; Palcic, I.; Polajnar, A. (2008). Bullwhip effect problem in supply chains, Advances in production engineering and management, Vol. 3, 45-55

[7] Cachon, G.P.; Randall, T.; Schmidt, G.M. (2007). In Search of the Bullwhip Effect, Manufacturing \& Service Operations Management, Vol. 9, 457-479

[8] Croson, R.; Donohue, K. (2003). Impact of POS Data Sharing On Supply Chain Management: An Experimental Study, Production and Operations Management, Vol. 12, 1-11

[9] Disney, S.M.; Towill, D.R. (2003). The effect of vendor managed inventory (VMI) dynamics on the Bullwhip Effect in supply chains, International Journal of Production Economics, Vol. 85, 199-215

[10] Dolgui, A.; Proth, J.M. (2010). Supply Chain Engineering: Useful Methods and Techniques. Springer-Verlag London Limited

[11] Forrester, J. W. (1961). Industrial Dynamics, MIT Press, and John Wiley \& Sons, Inc, New York

[12] Gaalman, G.; Disney, S. M. (2007). On bullwhip in a family of order-up-to policies with ARMA $(2,2)$ demand and arbitrary lead-times, International Journal of Production Economics, Vol. 121, 454-463

[13] Hoberg, K.; Bradley, J. R.; Thonemann, U. W. (2007). Analyzing the effect of the inventory policy on order and inventory variability with linear control theory, European Journal of Operational Research, Vol. 176, 1620-1642

[14] Janamanchi, B.; Burns, J. R. (2007). Reducing bullwhip oscillation in a supply chain: a system dynamics model-based study, International Journal of Information Systems and Change Management, Vol. 2, 350-371

[15] Kahn, J. (1987). Inventories and the volatility of production, American Economic Review, Vol. 77, 667-679

[16] Lee, H. L.; Padmanabhan, V.; Whang, S. (1997a). Information distortion in a supply chain: The bullwhip effect, Management Science, Vol. 43, 546-558

[17] Lee, H. L.; Padmanabhan, V.; Whang, S. (1997b). the Bullwhip Effect in Supply Chains, Sloan Management Review, Vol. 38, 93-102

[18] Liu, H.; Wang, P. (2007). Bullwhip Effect Analysis in Supply Chain for Demand Forecasting Technology, Systems Engineering - Theory \& Practice, Vol. 27, 26-33

[19] Mahnam, M.; Yadollahpour, M.R.; Famil-Dardashti, V.; Hejazi, S.R. (2009). Supply chain modeling in uncertain environment with bi-objective approach, Computers \& Industrial Engineering, Vol. 56, 1535-1544

[20] Metters, R. (1997). Quantifying the bullwhip effect in supply chains, Journal of Operations Management, Vol. 15, 89-100.

[21] Ouyang, Y. (2007). The effect of information sharing on supply chain stability and the bullwhip effect, European Journal of Operational Research, Vol. 182, 1107-1121

[22] Portes, A. N.; Vieira, G. E. (2006). The Impact of Vendor Managed Inventory (VMI) on the Bullwhip Effect in Supply Chains, Proceedings of the Third International Conference on Production Research - Americas' Region

[21] Ravichandran, N. (2006). Managing Bullwhip Effect: Two Case Studies, Working Paper No. 2006-08-01, IIM (Indian Institute of Management)

[22] Sterman, J. D. (1989). Modeling Managerial Behavior: Misperceptions of Feedback in a Dynamic Decision Making Experiment, Management Science, Vol. 35, 321-339

[23] Sterman, J. D. (2006). Bullwhip Effect in Supply Chains: A Review of Methods, Components and Cases, chapter 2: Operational and Behavioral Causes of Supply Chain Instability, Edited by Octavio A. Carranza Torres and Felipe A. Villegas Morán, Palgrave Macmillan

[24] Thonemann, U. W. (2002). Improving supply-chain performance by sharing advance demand information, European Journal of Operational Research, Vol. 142, 81-107

[25] Wu, D.; Katok, Y. E. (2006). Learning, communication, and the bullwhip effect, Journal of Operations Management, Vol. 24, 839-850 